W. Child - "Wittgenstein, Seeing-as, and Novelty" - forthcoming in M. Beaney and B. Harrington eds., Aspect Perception after Wittgenstein: Seeing-As and Novelty, London: Routledge.

\title{
Wittgenstein, Seeing-As, and Novelty
}

\author{
William Child
}

\section{Introduction}

What is the relation between novelty, creativity, and innovation, on the one hand, and the phenomenon of seeing-as, on the other? And what if anything does Wittgenstein's work on seeing an aspect teach us about that relation?

It is common to say that someone who acquires a new set of concepts or a new system of belief comes to see things in a new way. In that vein, Thomas Kuhn famously likens paradigm shifts in science to Gestalt shifts in perception. ${ }^{1}$ The shift from a geocentric to a heliocentric cosmology, he thinks, or from Newtonian physics to Einsteinian physics, is like the shift from seeing the duck aspect of the duck-rabbit figure to seeing its rabbit aspect: when we shift from one paradigm to another, we come to see the world in a new way - as containing things and properties that we did not see before. Similarly, religious conversion is often described as involving a transformation in the convert's way of seeing the world. In one sense, everything remains as it was before; but in another sense, everything is seen differently. Or again, the development of the concept of sexual harassment is said to have changed people's way of seeing things; a remark that would formerly have been seen as a joke, for instance, came to be seen as an instance of harassment. In these and other cases it is extremely natural to describe the acquisition of new concepts, or a new theory, or new knowledge, as involving coming to experience the world in a new way. But how seriously should we take that idea and what should we make of it?

I shall consider three issues. First, is there any special connection between seeing-as and novelty: a connection that is absent from the case of grasping familiar concepts, theories or knowledge? Second, is there an explanatory relation between seeing-as and novelty? Is conceptual or theoretical innovation explained by the fact that the innovator sees things in a new way? Third, whatever association there is between seeing-as and novelty, is it important? Why, if at all, does it matter that someone who grasps new concepts experiences things in a new way? Would she be any worse off if she simply operated with the new concepts in a way that left her experience of the world unaffected?

Before proceeding, I note a preliminary point about the notion of novelty. We can distinguish between two kinds of case in which someone acquires a new theory or set of concepts. On the one hand, there is the case of genuine theoretical or conceptual innovation: the case where a person devises a theory or set of concepts that no-one has grasped before. On the other hand, there is the case where she acquires an existing theory or set of concepts: the theory she acquires is new to her; but it is already understood by others. That is an important distinction; it is more difficult, and requires more creative effort, to formulate an original theory than to learn an existing theory from other people. But with respect to the links between seeing-as and novelty, the distinction seems less important. In both cases, I move from not understanding to understanding; in both cases, the theory that I come to grasp is new for me; in both cases, I come to see phenomena, or patterns, or connections that I did not see before. In exploring the connections between seeing-as and novelty, therefore, I shall generally use the notion of novelty in an inclusive sense: for the purposes of this discussion, 
W. Child - "Wittgenstein, Seeing-as, and Novelty" - forthcoming in M. Beaney and B. Harrington eds., Aspect Perception after Wittgenstein: Seeing-As and Novelty, London: Routledge.

theories or concepts are novel if they are new for the person grasping them, even if they are not novel from the perspective of humanity as a whole. ${ }^{2}$

\section{Is there a special connection between seeing-as and novelty?}

Is there a special connection between seeing-as and novelty; a connection that is absent from situations where someone applies familiar concepts in straightforward and familiar cases? The following argument might suggest that there is no special connection. Suppose we accept that coming to grasp a new theory or set of concepts involves coming to see things in a new way. If conceptual innovation involves seeing things in a new way, there must have been some way in which the innovator saw things before: an old way of seeing, associated with the old system of concepts, just as the new way of seeing things is associated with the new system of concepts. So, if there is a connection between seeing-as and novelty, it is hard to avoid the conclusion that grasping any set of concepts involves seeing-as: seeing things in some particular way. According to this argument, there is a quite general connection between the concepts one grasps and the way one sees the world: the connection between grasping new concepts and seeing things in a new way is simply a product of that more general connection. ${ }^{3}$

There is some plausibility in that argument. But Wittgenstein's discussion of seeing an aspect suggests a more nuanced position. On this more nuanced position, there is indeed a general connection between seeing-as and grasping concepts. But there are also links between seeing-as and novelty that go beyond that general connection. We can work up to that position by considering some details of Wittgenstein's discussion.

Does Wittgenstein think there is a special connection between seeing aspects and novelty? Or does he think that seeing-as is a perfectly general phenomenon? On the one hand, he draws particular attention to a range of phenomena that specifically involve novelty or change: noticing an aspect, experiencing a change of aspects, an aspect's dawning or lighting up. ${ }^{4}$ On the other hand, he talks about the 'continuous seeing' of an aspect, which seems independent of any change or novelty (see PPF §118). What, in his view, is the connection between these two kinds of phenomena? On one interpretation, Wittgenstein takes continuous aspect-perception as the basic case; the cases involving novelty and change (noticing an aspect, experiencing a change of aspects etc.) are merely upshots or manifestations of that basic phenomenon. ${ }^{5}$ On a different interpretation, change and novelty are basic to Wittgenstein's conception of seeing-as: those are the phenomena he is really interested in and, in his view, the phenomenon of continuous aspect perception occurs only in the context of some possible change. ${ }^{6}$ Which interpretation best captures Wittgenstein's discussion?

Before addressing that question, we should register a note of caution. It would be a mistake to try to organize the whole range of phenomena that Wittgenstein discusses as instances of seeing an aspect in terms of a single distinction between the continuous seeing of an aspect, on the one hand, and noticing an aspect, or experiencing a change of aspects, or an aspect's lighting up, on the other hand. It would be similarly mistaken to press the question, 'Exactly what does Wittgenstein take seeing-as to involve?' In his view, seeing-as is not a single, homogeneous phenomenon. Part of his point is that 'there is an enormous number of interrelated phenomena and possible concepts' in this area (PPF §155). He notes that the concept of what is seen is 'very elastic' (PPF §147). And he insists that 'there is not one genuine, proper case' of describing what is seen (PPF §160). Thus, if we apply what Wittgenstein says to the case where someone sees, say, a portrait of Elizabeth I, we can distinguish at least four senses or levels of seeing that may be involved. First, the person may see the picture without being conscious of its qualities at all. ${ }^{7}$ Second, he may see it, and be 
W. Child - "Wittgenstein, Seeing-as, and Novelty" - forthcoming in M. Beaney and B. Harrington eds., Aspect Perception after Wittgenstein: Seeing-As and Novelty, London: Routledge.

aware of the colours and shapes it contains, without seeing it as a picture of Elizabeth I. And, as Wittgenstein says, that is consistent with his knowing that it is a picture of Elizabeth I and being able to work out various things about her from the picture. Third, he may see it as a picture of Elizabeth I: he sees her in the picture; and, in Wittgenstein's phrase, he views the picture as the person it represents (PPF §197). Fourth, he suggests, there is a further concept of seeing-as:

[the concept] of a seeing-as which occurs only while I am actually concerning myself with the picture as the object represented.

I could say: a picture is not always alive for me while I am seeing it.

'Her picture smiles down on me from the wall.' It need not always do so, whenever my glance lights on it (PPF §§199-200).

What all that suggests is something that we would anyway expect on general grounds. Wittgenstein's discussion explores a large number of related but different perceptual phenomena. He does not aim to explain or analyse the phenomena in terms of anything more basic. (So, for instance, he rejects the assumption that the various phenomena of seeing-as can be explained in terms of a bipartite distinction between experience on the one hand and thought on the other. ${ }^{8}$ ) Nor does he hope to formulate a general theory about seeing-as. On the contrary, he explicitly eschews such ambitions:

(In giving all these examples, I am not aiming at some kind of completeness. Not a classification of psychological concepts. They are only meant to enable the reader to cope with conceptual unclarities.) (PPF §202)

In the light of that, we should be cautious about the idea that Wittgenstein thinks of one kind of phenomenon (continuous seeing of an aspect, say, or noticing an aspect) as the basic case, or that his main interest is focused on one class of cases rather than another.

That point is well taken. But, having acknowledged it, we can still consider our question about Wittgenstein's attitude to the relation between seeing-as and novelty. As we have noted, he is happy to talk about the continuous seeing of an aspect. And he is happy to say that someone who only ever sees the duck-rabbit picture as a picture-rabbit is a case of seeing-as: he sees the figure as a picture-rabbit (PPF §121). In such a case, seeing-as seems to have no essential connection with novelty: with noticing an aspect, experiencing a change of aspect, or an aspect's lighting up. And visual experience seems quite generally to involve seeing-as in this sense: I see the object on my desk as a mug (rather than merely knowing that it is a mug); I see the mouthpiece of my French Horn as a mouthpiece (and do not have to work out that it is a mouthpiece); I see the thing in the shop window as a bicycle; and so on.

However, someone who thinks that the real focus of Wittgenstein's interest is this inclusive notion of seeing-as must explain why he gives so much attention to the more limited and specific phenomena of novelty and change of aspect. At least two explanations might be suggested. One suggestion is that the reason why Wittgenstein emphasizes examples of aspect-change and so forth is simply that they are particularly good cases for establishing a point he wants to make about visual experience in general. The general point, on this view, is that perception is theory-laden: our awareness of the world does not present us with a mere mosaic of shapes and colours, which we have to interpret as experience of objects and properties around us; on the contrary, the objects and properties are built into the intrinsic nature of the experience. The phenomenon of aspect-change is then said to provide compelling support for this general point. For, it is said, it is simply obvious that aspectchange is an experiential phenomenon and not a merely cognitive one; the idea that our experience remains the same throughout, and that what changes is just the interpretation we put on it, obviously falsifies the phenomenology. But once that point is appreciated for the special case of aspect-change, the more general point can be seen to apply to all visual experience. 
W. Child - "Wittgenstein, Seeing-as, and Novelty" - forthcoming in M. Beaney and B. Harrington eds., Aspect Perception after Wittgenstein: Seeing-As and Novelty, London: Routledge.

A second putative explanation for Wittgenstein's focus on cases where aspects change or light up starts from Wittgenstein's insistence that it is only appropriate to say ' $S$ sees $x$ as an $F$ ' (or even, that the utterance only makes sense) if there is some contrast or ambiguity in question. In a straightforward case where I recognize a familiar object - a cup, say - for what it is, and have no thought of its being anything else, it would, he thinks, be inappropriate (or even senseless) for me to say 'I see the cup as a cup'; that utterance 'would not be understood' (PPF §122). Similarly, if I see the duck-rabbit figure and have no idea that it is an ambiguous figure, it would be inappropriate for me to say 'I see it as a picture-rabbit'; I should simply say 'I see a picture-rabbit'. That makes it natural for Wittgenstein's discussion of seeing-as to focus on instances of aspect shift or aspect dawning, where - in the nature of the case - there is always a relevant contrast, which guarantees that talk of seeing-as will always be appropriate. But, on the current suggestion, it is compatible with that to hold that Wittgenstein takes the phenomenon of seeing-as to be a ubiquitous one. For even if I am not aware of the ambiguity, so cannot appropriately say, 'I'm seeing the figure as a picturerabbit', it is still true that I do see it as a picture-rabbit; and others who are aware of the ambiguity can appropriately say of me, 'He is seeing it as a picture-rabbit' (PPF §121). So, on this view, Wittgenstein means to be discussing a quite general phenomenon; but there is a good reason why his discussion of seeing-as tends nonetheless to focus on the narrower category of cases where aspects change or light up.

What should we make of these arguments? Wittgenstein certainly does employ a notion of seeing-as that is intended to apply very generally - including in cases where there is no kind of novelty in play. But it would be wrong to conclude that the reasons for his particular focus on cases of novelty are exhausted by the considerations we have just sketched. For, as he presents things, the character of the experiences involved in cases where aspects change or light up goes beyond anything that is intelligible in terms of the more general phenomenon. In a shift of aspects (say, the shift from seeing the rabbit-aspect of the duck-rabbit picture to seeing the duck-aspect), there is not just a change in our experience: a change from seeing things one way to seeing them another way. There is also an experience of change: an experience of something changing (or seeming to change). And that experience of change itself has a distinctive character: the person who experiences a change of aspects is aware of things changing in one respect but being unchanged in another. As Wittgenstein puts it:

I observe a face, and then suddenly notice its likeness to another. I see that it has not changed; and yet I see it differently (PPF §113). Or again:

The expression of a change of aspect is the expression of a new perception and, at the same time, an expression of an unchanged perception (PPF §130)

That feature of a change in aspects is plainly not present in the general case of seeing-as. Nor is it explicable in terms of anything that is.

Parallel remarks apply in the case of the dawning of an aspect. Consider the case where I am suddenly struck by the likeness between someone and his father (PPF §111-13, $\S \S 239 \mathrm{ff})$. When I am struck by the resemblance, there is a change in my experience. But the change is not just a shift from one way of seeing things to another. Being struck by a likeness - like being aware of a change - is itself an experience. And it is an essentially transitory experience; it is not something that could be a permanent feature of my awareness of anything. As Wittgenstein puts it: 'The likeness strikes me, and its striking me fades' (PPF §244); 'There is a physiognomy in the aspect, which then fades away' (PPF §238). So in this case, as with the case of aspects changing, there is something present in the novelty-involving case that is not a feature of the general case of seeing an aspect and cannot be accounted for in terms of that general case. Wittgenstein is certainly interested in a general phenomenon of 
W. Child - "Wittgenstein, Seeing-as, and Novelty" - forthcoming in M. Beaney and B. Harrington eds., Aspect Perception after Wittgenstein: Seeing-As and Novelty, London: Routledge.

seeing-as. But his discussion of the novelty-involving cases highlights features that go beyond the more general phenomenon.

A further issue is suggested by Wittgenstein's discussion of aspect-blindness. As we have just seen, the general phenomenon of continuous aspect-perception is distinct from the particular phenomena of aspect-change and aspect-dawning in this sense: the particular phenomena cannot be accounted for in terms of the more general phenomenon. But is the general phenomenon distinct in a further sense: can the general ability to see something as something exist without the ability to have experiences of aspect-shift, aspect-dawning, and so forth?

Empirical evidence suggests that it can: that there is a stage in human development at which children do have continuous seeing-as without the ability to see changes in aspect. ${ }^{9}$ For instance, they react to pictures as we do: they see the rabbit aspect of a picture-rabbit, and do not merely interpret the picture as a representation of a rabbit. And, with an ambiguous picture, they can see it in one way in one context and in a different way in a different context: they see the duck-rabbit picture as a picture-rabbit when it is surrounded by other pictures of rabbits, and as a picture-duck when surrounded by other pictures of ducks. But they cannot see the ambiguous picture shift from one aspect to the other; nor, while seeing something as a picture-rabbit, can they try to see it as something else, or acknowledge that it could be something else. If that is the right way of understanding the data, then the ability to see a picture shift from one aspect to another is indeed a separate ability in the further sense defined above: someone can have the ability to see aspects without being able to experience shifts of aspect. ${ }^{10}$

Where does Wittgenstein stand on this question? The evidence is equivocal. In a remark originating in notebooks from February 1948, he writes: 'Of course it is imaginable that someone might never see a change of aspect, the three-dimensional aspect of every picture always remaining constant for him. But this assumption doesn't interest us' (RPP II §480). The first sentence of that remark might suggest that Wittgenstein agrees that someone can see a schematic cube as a three-dimensional cube, say, without being able to experience a shift from one aspect to the other. But the second sentence cancels that suggestion. Someone may, as a matter of empirical fact, never see a change of aspect. Nonetheless, Wittgenstein seems to suggest, that empirical possibility is consistent with there being a necessary connection between the ability to see the schematic cube as a cube and the ability to see aspects change, even if that latter ability is never in fact triggered.

A remark from the slightly later discussion in 'Philosophy of Psychology: A Fragment', however, might suggest a different view. Here Wittgenstein is discussing the double cross figure, which can be seen as a white cross on a black ground and as a black cross on a white ground; he calls these 'the A aspects' (see PPF §212). He writes:

The aspect-blind man is supposed not to see the A aspects change. But is he also supposed not to recognize that the double cross contains both a black and a white cross? So if told 'Show me figures containing a black cross among these examples', will he be unable to manage it? No. He is supposed to be able to do that, but not to say: 'Now it's a black cross on a white ground!' (PPF §257).

It is explicit here that the aspect-blind person cannot see the change of aspect. But can he see the double-cross figure as a black cross on a white ground and, separately, as a white cross on a black ground? That depends on how we understand Wittgenstein's use of 'recognize'11. If 'recognizing' that the figure contains a black cross involves seeing it that way (rather than merely knowing, or working out, that it contains a black cross), then this will be a case where Wittgenstein allows that a person can see something as something without being able to see the relevant aspects changing. But if 'recognizing' that the figure contains a black cross is consistent with not seeing it that way, then Wittgenstein's example provides no evidence for 
W. Child - "Wittgenstein, Seeing-as, and Novelty" - forthcoming in M. Beaney and B. Harrington eds., Aspect Perception after Wittgenstein: Seeing-As and Novelty, London: Routledge.

his acceptance of that possibility. I shall not try to resolve here the question of exactly what patterns of deficits Wittgenstein takes to be intelligible in this area. As I have said, the evidence about his view seems equivocal. That is perhaps unsurprising, since Wittgenstein's discussion of aspect-blindness is deliberately open-ended and exploratory. He is not setting out to describe an actual phenomenon with which we are all familiar. Rather, he uses the imagined phenomenon of aspect-blindness as a way of probing the familiar phenomenon of seeing aspects. As he puts it: 'I form a concept and ask myself how one might follow through with it consistently. What we feel would deserve to be called that' (RPP II 491).

It is time to take stock. We started this section with the question, whether there is a special connection between seeing-as and novelty, or whether the relation between seeing things in a new way and grasping new concepts or theories is simply a manifestation of a more general phenomenon of seeing-as. The lessons we have drawn from Wittgenstein's discussion of seeing aspects cast light on that original question. Suppose we accept that grasping new concepts or theories involves coming to see things in a new way. That is in part a manifestation of a more general phenomenon: grasping any system of concepts, new or old, involves seeing things in a certain way. But there is something special about cases of novelty that goes beyond that general phenomenon. When I come to accept a new theory I shift from an old way of seeing things to a new way. But in some cases, at least, there is not merely a change in the way I experience things. There is also an experience of change: an awareness of a change in the way I am understanding or conceptualizing things. There may also be a sense of things that had previously been puzzling suddenly making sense. And so on. Such experiences are part of the phenomenon of conceptual or theoretical novelty. They go beyond a mere shift from an old way of seeing things to a new way. And they have no analogue in the general case of applying familiar concepts. To that extent, then, there really is something special about the specific connection between seeing-as and coming to grasp new concepts or theories.

Even if we accept that point, however, we may still wonder about the significance of the connection. Is the special connection between seeing-as and conceptual or theoretical novelty simply a matter of doing descriptive justice to the facts about our experience? Or does seeing-as in some way help to explain conceptual innovation?

\section{Does seeing-as explain innovation?}

It may be tempting to think that seeing-as can help to explain creativity or innovation. It is her ability to see things in new or unorthodox ways, we may think, that explains the innovator's success in discovering or devising new theories. Relatedly, it can be tempting to think that seeing-as helps to explain our grasp of new concepts. Indeed, it might be argued that the only way of explaining how someone can come to grasp a completely new system of concepts is in terms of the idea that she comes to see things in a new way. For, the thought would go, if the concepts she acquires really are new ones, then she cannot come to understand them by grasping a definition or explanation formulated in terms of concepts she already understands; what makes the new concepts new ones is precisely that they cannot be captured in that way. But there must be some way in which she comes to grasp these new concepts and categories. And the idea that the learner comes to see things in a new way seems to fit the bill: it recognizes that the new concepts cannot be captured in terms of the old ones; but, on the current view, it avoids leaving our ability to acquire new concepts as a complete mystery. A version of the same idea is expressed in the appealing thought that a person's grasp of a rule ultimately depends simply on her seeing things in the right way. As Wittgenstein says, there must be 'a way of grasping a rule which is not an interpretation' (PI §201). And, on the current proposal, what someone has when she grasps a rule without an 
W. Child - "Wittgenstein, Seeing-as, and Novelty" - forthcoming in M. Beaney and B. Harrington eds., Aspect Perception after Wittgenstein: Seeing-As and Novelty, London: Routledge.

interpretation is a kind of perceptual capacity: she sees this, this, and this as correct applications of the rule at the relevant points.

I said that it may be tempting to think that we can appeal to seeing-as to explain theoretical innovation or the acquisition of new concepts. If we follow Wittgenstein, however, it is a temptation we should resist. He himself shows no inclination at all to appeal to seeing-as to give such explanations. And, as we shall see, though his discussion leaves room for seeing-as to figure in a certain kind of explanation, of limited scope, it does not leave room for the kind of explanation that it might be tempting to envisage.

Wittgenstein asks: 'How can a language-game suddenly become clear to a child?'

(LW I 873). The particular case he is considering is the 'language-game' of ascribing pain to people; a language-game that acknowledges the possibility of pretence, and includes expressions of both belief and doubt. In learning this practice, Wittgenstein says, one 'learns the use of the expression "to be in pain" in all its persons, tenses, and numbers, but also in connection with negation and the verbs of opinion’ (LW I 874). How does a child come to grasp that practice?

Today for the first time he said 'I believe she's in pain'. But that's not enough. So I must assume that in what followed he showed the he hadn't simply repeated somebody's words. In short, that his utterance was the beginning of a game, and that he was able to continue with it. Today, so it seemed, the game had become clear to him (LW I 874).

Then comes the question quoted above: how can the language-game suddenly become clear to the child? Wittgenstein responds:

God only knows - One day it starts doing something. An analogue might be the child learning a board game which he sees played daily (LW I 873).

Wittgenstein does not say that the reason why the practice suddenly becomes clear to the child is that he suddenly sees things in the right way. On the contrary, there is in his view no informative answer to the question, how the practice suddenly becomes clear: at least, there is no informative answer at the level of personal-level, common-sense psychology, which is, for him, the level at which philosophy operates. The fact is that the practice does suddenly become clear to the child: at one point, he has not grasped it; at another point, he has. That he has grasped it consists in his ability to do the right thing: to use 'She's in pain', 'I believe she's in pain', 'I doubt whether she's in pain', and so on appropriately. And that is all we can say. We cannot explain how the practice becomes clear to the child: how he suddenly comes to master the language-game; how he moves from not understanding to understanding. As Wittgenstein puts it in another context, 'there is no how' (see RPP I 428). Of course there is in principle an account to be given of what went on in the child's brain and nervous system when he acquired the new ability. But, in Wittgenstein's view, such an account cannot give us the sort of explanation we wanted when we asked how a practice can suddenly become clear.

The remark from LW I 873 concerns a particular case. But the view Wittgenstein expresses - that there is no informative answer to the question, how a practice suddenly becomes clear to someone - is quite general. In particular, Wittgenstein does not suggest that we can explain someone's suddenly grasping a practice by appealing to the fact that she suddenly saw things in a new way.

That might seem puzzling. For doesn't Wittgenstein himself use the vocabulary of seeing in connection with concept-acquisition: specifically, in connection with grasping a rule? In teaching someone a rule, he says, we start by explaining how the rule is to be applied. If that explanation is not understood, we can switch to another, or supplement the first explanation with a second. But at some point, we can give no further explanation. And at that point, all we can say is 'Don’t you see .... ?’ (see e.g. PI §185, Z 302). The person 
W. Child - "Wittgenstein, Seeing-as, and Novelty" - forthcoming in M. Beaney and B. Harrington eds., Aspect Perception after Wittgenstein: Seeing-As and Novelty, London: Routledge.

who has grasped the rule sees how to go on: she sees what the rule requires at each successive step. The person who does not grasp the rule, by contrast, does not see how to go on; she does not see the regularity or pattern involved in the correct applications of the rule. But in that case, we might think, we surely can appeal to facts about how someone sees things in order to explain her grasp of a rule. Why did Anne grasp the rule for developing the series 2, 4, 6, $8 \ldots$ while Bob did not? Because she saw the pattern in the series while he did not; she saw $1000,1002,1004 \ldots$ as the correct continuation of the series, while he did not. So, at least, one might be tempted to think.

In Wittgenstein's view, however, the putative explanations are illusory. The fact that Anne sees 1000, 1002, $1004 \ldots$ as the correct continuation of the series is not something that explains her grasp of the rule for developing the series; it is part of what her grasp of the rule consists in. Similarly, Bob's failure to see the pattern in the series is not something else about him, distinct from the fact that he does not grasp the rule for developing the series. On the contrary, his failure to see the successive steps of the series as the correct continuation of the series just is his failure to grasp the rule for developing the series; so we cannot use the former to explain the latter.

What about the broader suggestion that seeing-as helps to explain creativity or innovation: that the conceptual or theoretical innovator's achievement in devising her new concepts or theory can be explained in part by reference to the fact that she sees things in a new way? The assessment of that suggestion depends on what the new way is in which the innovator sees things. We can distinguish two kinds of case. In cases of the first kind, seeing things in the new way is simply a matter of seeing them in terms of the new concepts or theory. In cases of the second kind, the new way of seeing is independent of grasp of the new concepts or theory. Seeing-as can help to explain innovation in the second kind of case, but not in the first.

Suppose we accept that, in coming to grasp a new system of concepts or a new theory, one thereby comes to see things in a new way. On this view, seeing things in the new way is seeing them in terms of the new concepts or theory. But in that case, the fact that someone sees things in this new way cannot explain how she formed, or was able to form, her new concepts or theory; on the contrary, her seeing things in the new way presupposes her grasp of the new concepts or theory. Conceptual or theoretical innovation may involve seeing things in a new way; but the innovator's achievement is not explained by her seeing things that way.

In the second kind of case, by contrast, one can see things in the new way without already grasping the new concepts or theory. Suppose someone sees a new pattern in the phenomena; or she sees similarities between different cases that she had not previously noticed. That prompts her to look for something that explains the pattern. She devises her new theory to provide such an explanation. In a case of that sort, the innovator's new way of seeing things really can help to explain the formation of the new theory. What makes room for explanation is the fact that seeing the pattern was distinct from grasping the theory; after all, she saw the pattern before she formulated the theory. For example, suppose an experimenter suddenly sees the pulses of electromagnetic radiation emanating from a particular point in the sky in a new way; she sees them as resembling the flashes of a lighthouse. Seeing the pulses in that way suggests a particular theory about their source: the pulses, she hypothesizes, are produced by the rotation of a star that emits a constant beam of radiation, just as the flashes of a lighthouse are produced by the rotation of a lamp that emits a constant beam of light. But the new way in which she saw the pulses - as resembling the flashes of a lighthouse - was distinct from the theory she subsequently devised to explain the phenomenon; she saw the pulses in that way before she devised the theory. In that 
W. Child - "Wittgenstein, Seeing-as, and Novelty" - forthcoming in M. Beaney and B. Harrington eds., Aspect Perception after Wittgenstein: Seeing-As and Novelty, London: Routledge.

circumstance, her seeing the pulses as she did really does help to explain her formulation of the new theory.

We asked whether seeing-as can explain conceptual or theoretical innovation. The discussion of this section has yielded the following points. First, Wittgenstein himself does not appeal to seeing-as to explain the acquisition of new concepts or the mastery of new practices. In his view, philosophy cannot explain how we make the transition involved in coming to master new concepts or practices. Second, the idea that the innovator's success in discovering new theories is explained by the fact that she sees things in new or unorthodox ways can be developed in two different ways. In one version, the idea should be rejected: if the new way of seeing itself involves the new theory, it cannot explain the development of the theory. In a different version, the idea contains an important truth: in cases where the new way of seeing is independent of the new theory, it may help to explain the development of the theory; but even in such cases - if Wittgenstein is right - there is bound to remain something basic or inexplicable in the innovator's act of creation.

\section{Is seeing-as essential to understanding?}

In the previous sections we have been supposing, for the sake of argument, that when someone comes to grasp new concepts or a new theory she comes to see things in a new way. But is that supposition true? Couldn't someone grasp the new concepts or theory without any difference at all in the way she sees things? After all, you grasp a word or concept if you use it in the right way: or at least, if you are a sufficiently fluent participant in the practice of using it. ${ }^{12}$ That is a matter of employing it appropriately, responding appropriately to its use by others, and so on. If you do that, you grasp the word or concept. The way you experience things seems irrelevant. Saying that someone who grasps a new theory sees things in a new way may be a good metaphor. But is there any reason to think that it is literally true?

Wittgenstein raises a closely related point. He writes:

The importance of [the concept of aspect-blindness] lies in the connection between the concepts of seeing an aspect and experiencing the meaning of a word. For we want to ask, 'What would someone be missing if he did not experience the meaning of a word?'

What would someone be missing, who, for example, did not understand the request to pronounce the word 'till' and to mean it as a verb - or someone who did not feel that a word lost its meaning for him and became a mere sound if it was repeated ten times over? (PPF §261)

And similarly:

When I supposed the case of a 'meaning-blind' man, this was because the experience of meaning seems to have no importance in the use of language. And so because it looks as if the meaning-blind could not lose much (RPP I 202). ${ }^{13}$

Wittgenstein's comments focus on experiences of a particular kind, which he calls 'experiences of meaning'. But the question he is asking can be generalized: if understanding a word is a matter of grasping its use, how can the way we experience things have any essential connection with whether or not we understand the word? And why should grasping a new word or concept have any important connection with coming to experience things in a new way?

One response to those questions is to accept that the talk of seeing in this context is simply a façon de parler; acquiring new concepts or theories does not literally involve a change in the way we see things. We find it natural to say that the person who grasps a new theory or system of concepts sees things in a new way. But we could equally well, and more accurately, say that the person with a new theory or system of concepts conceives or 
W. Child - "Wittgenstein, Seeing-as, and Novelty" - forthcoming in M. Beaney and B. Harrington eds., Aspect Perception after Wittgenstein: Seeing-As and Novelty, London: Routledge.

understands or describes things in a new way. The natural association between grasping new concepts and seeing things in a new way is, on this view, an example of the general way in which our talk of thought, belief, and understanding is suffused with visual metaphors: 'I don't see what you mean', 'She saw the solution', 'He was blind to the implications', and so on. In each case, it is claimed, the phenomena in question are essentially cognitive, not experiential.

How should we react to that suggestion? One possibility is to concede the basic point - that there is no general connection between grasping new concepts and experiencing things in a new way - but to insist that in some cases the person who grasps new concepts really does thereby come to see things in a new way. There is, as Wittgenstein points out, a difference between, on the one hand, merely knowing that something is an $F$, or interpreting it as an $F$, and, on the other hand, seeing it as an $F$. And though in some cases the person who acquires new concepts merely comes to conceive or describe things in terms of the new concepts, in other cases she does more than that; in a perfectly literal, non-metaphorical sense, she comes to see things as falling under those concepts. In short: if it is a mistake to say that acquiring new concepts always involves seeing things in a new way, it is equally mistaken to say that it never involves a new way of seeing. That is an important corrective to the suggestion of the previous paragraph. But does Wittgenstein's treatment of seeing-as suggest any stronger response?

I will explore two lines of thought that might be developed from Wittgenstein's discussion. The first line of thought adds modal force to the point just made: it is not just that a person who grasps a system of concepts may experience things in terms of those concepts; for every person, there must be some concepts for which that is true. The second line of thought focuses on what it takes for someone to understand a concept and argues that we can distinguish different standards, or notions, of understanding. By one standard, we can agree, someone who applies a set of concepts appropriately without seeing things in terms of those concepts counts as understanding the concepts in question; by another standard, however, she does not. We can consider these two lines of thought in turn.

Consider, first, the case of linguistic understanding. It is a fundamental insight of Wittgenstein's that there must be some cases in which one understands words or utterances immediately, without interpretation (see PI §201). Understanding a word or an utterance can sometimes require an act of interpretation: as when I have to consult a dictionary in order to understand some word or phrase in Chaucer's Canterbury Tales. But it could not be the case that all understanding involved interpretation in that sense. If I could not understand the dictionary's definitions of Chaucer's words without reference to a second dictionary, and I couldn't understand the second dictionary's definitions without reference to a third dictionary, and so on, then I could never understand Chaucer at all. According to the first line of thought, a parallel argument shows that there must be some cases of seeing-as: cases in which one sees an object as falling under a given concept. Identifying something as a such-and-such sometimes requires an act of interpretation: as when I work out that an unfamiliar object is a bottle-opener without seeing it that way. I detect various properties of the object; I interpret the object as a bottle-opener on the basis of its possession of those other properties. But it could not be the case that all concept application worked like that. Suppose that the only way to identify an object as an F was to interpret it as an F on the basis of its being $G$, and the only way to identify the object as being $G$ was to interpret it as being $G$ on the basis of its being $\mathrm{H}$, and so on. Then we could never identify objects as falling under concepts at all. So there must be some cases in which one simply sees an object as falling under a concept, rather than merely interpreting the object that way. ${ }^{14}$ To the best of my knowledge, Wittgenstein does not present that argument explicitly in his discussion of seeing and seeing-as. But he does explicitly argue that seeing-as cannot be understood in terms of 
W. Child - "Wittgenstein, Seeing-as, and Novelty" - forthcoming in M. Beaney and B. Harrington eds., Aspect Perception after Wittgenstein: Seeing-As and Novelty, London: Routledge.

interpretation (see PPF $\S \S 248-9$ ). And the argument just sketched is certainly suggested by Wittgenstein's argument about linguistic understanding and interpretation. Wittgenstein argues that there is a way of grasping a rule that is not an interpretation (PI §201). Similarly, on the present argument, there is a way of identifying an object as falling under a concept that is not an interpretation: namely, seeing it as falling under the concept.

The second line of thought focuses on the idea of understanding. We began this section with a question: if understanding a concept is a matter of using it appropriately, how can the way someone experiences things be relevant to whether or not they understand? One response to that question is to ask whether it is true that understanding a concept requires no more than using it appropriately. At least: even if there is a legitimate sense in which one understands a concept provided only that one uses it appropriately, isn't there a different sense in which understanding a concept requires, in addition, that one should experience things in a particular way? ${ }^{15}$

We can start with a different case. In Remarks on the Philosophy of Psychology volume II, Wittgenstein raises the question, 'Can a human being understand what "fearing" is without knowing fear?' (RPP II 26). 'Knowing' here is a translation of the verb kennen. So what Wittgenstein is asking is whether someone can understand what 'fearing' is without being acquainted with fear: without having felt fear. On one view, there is no reason at all why someone should have to have felt fear in order to understand the word 'fear'. All that is needed is the ability to use the word 'fear' appropriately: to apply it to cases in appropriate ways; to make appropriate connections with other words; and so on. And one could perfectly well do that without ever having felt fear. After all, doctors and psychiatrists can successfully identify sensations and emotions that they have never experienced themselves. They plainly have concepts of those sensations and emotions. The same, it may be said, is true for the simple concept of fear.

But it is possible to take a different view. If someone has never felt fear, we could say, she does not really know what fear is; she does not fully understand people's talk of fear. But why should we say that? Wittgenstein approaches that question by considering what the person who has never felt fear is thereby unable to do:

The question is: What kind of language-games can someone who is unacquainted with fear eo ipso not play? (RPP II 27; see also Z 267)

He highlights a deficiency in the person's mastery of the 'language-game' of ascribing fear to others:

One could say, for example, that he would watch a tragedy without understanding it. And that could be explained in this way: When I see someone else in a terrible situation, even when I myself have nothing to fear, I can shudder, shudder out of sympathy. But someone who is unacquainted with fear wouldn't do that. We are afraid along with the other person, even when we have nothing to fear; and it is this which the former cannot do. Just as I grimace when someone else is being hurt (RPP II 27).

That suggests that the ability to relate someone else's fear to feelings with which one is oneself familiar is an essential part of understanding what she is feeling as fear. Someone who has never felt fear might learn to apply the word 'afraid' to others in circumstances where they are indeed feeling fear. But she could not mean by 'fear' and 'afraid' what we mean by those words. For the meaning of those words on our lips, the suggestion goes, depends in part on our sympathetic response to others' fear: 'we are afraid' along with the other person. And the person who is unacquainted with fear can have no such sympathetic response to others' fear.

One response to this suggestion is that it fails to distinguish between understanding the word 'fear', on the one hand, and understanding the emotion of fear, or people who feel 
W. Child - "Wittgenstein, Seeing-as, and Novelty" - forthcoming in M. Beaney and B. Harrington eds., Aspect Perception after Wittgenstein: Seeing-As and Novelty, London: Routledge.

fear, on the other. Having felt fear, on this view, is not a necessary condition for understanding the word 'fear'. It may be a necessary condition for understanding the emotion, or the people who experience it. But that has nothing to do with understanding the word. Wittgenstein himself sometimes puts things in just that way. Consider this case, for instance:

It is . . . important as regards our considerations that one human being can be a complete enigma to another. One learns this when one comes into a strange country with entirely strange traditions; and, what is more, even though one has mastered the country's language. One does not understand the people (PPF §325, first emphasis added).

In Wittgenstein's example, I understand the language of these people whose lives and traditions I do not share; I know what their words mean. What I don't understand are the people themselves: I cannot see the point or attraction of thinking and behaving as they do; I cannot make sense of them in the way that I can make sense of people whose values and traditions are closer to my own. ${ }^{16}$

Wittgenstein seems, then, to offer us two different ways of thinking about the person who has never felt fear. It is common ground that such a person lacks the kind of sympathetic response to others' fear that we have: she does not understand what fear is like for the person who feels it. But there are different ways of describing her situation. On one view, she understands the word 'fear'; but she doesn't understand people's experience of fear. On a different view, she does not understand the word 'fear', precisely because she has no sympathetic understanding of those who are afraid. It is natural to ask which of those views is correct.

Wittgenstein's position, however, is that there is no need to choose between these two positions. There is, in his view, no hard-and-fast distinction between understanding words, on the one hand, and understanding people, on the other. There are numerous different aspects, or strands, of understanding, and correspondingly many different standards of what it takes to understand a use of language. Those different standards are equally legitimate. No one standard is more basic or theoretically significant than the others. It is just part of the concept of understanding that it has these different aspects, or strands. He writes:

We speak of understanding a sentence in the sense in which it can be replaced by another which says the same; but also in the sense in which it cannot be replaced by any other. (Any more than one musical theme can be replaced by another.)

In the one case, the thought in the sentence is what is common to different sentences; in the other, something that is expressed only by these words in these positions. (Understanding a poem.)

Then has 'understanding' two different meanings here? - I would rather say that these kinds of use of 'understanding' make up its meaning, make up my concept of understanding.

For I want to apply the word 'understanding' to all this (PI §§531-2).

Wittgenstein would say the same thing about the case we have been considering. There is a use of 'understand' on which one can understand the word 'fear' without knowing what fear feels like. There is another use of 'understand' on which one cannot. But that does not mean that the word 'understand' is ambiguous. Rather, these different kinds of use of 'understand' make up its meaning.

What does this discussion of the connection between understanding the word 'fear' and experiencing fear suggest about the connection between grasping concepts and seeingas? What we have seen in the case of 'fear' is that there is a sense in which one only understands the word 'fear' if one has felt fear oneself. Is there, similarly, a sense in which one only understands the concept $F$ if one experiences things as $F$ 's? There is a range of 
W. Child - "Wittgenstein, Seeing-as, and Novelty" - forthcoming in M. Beaney and B. Harrington eds., Aspect Perception after Wittgenstein: Seeing-As and Novelty, London: Routledge.

concepts, at least, for which it is very plausible that there is indeed such a sense of 'understand'. That certainly seems true for a range of simple perceptible properties. Someone who is colour blind might learn to distinguish red things on the basis of their physical properties, without ever seeing them as red. In one sense, she grasps the concept red. In another, she does not. (Alternatively: she grasps one concept of red; but she fails to grasp a different concept of red.) The same is true for many aesthetic properties. Someone might learn to distinguish minor chords from major ones on the basis of their structural characteristics, without ever hearing a chord as minor or being able to pick it out as minor on the basis of its sound. She might learn to distinguish pairs of words that rhyme from pairs that do not without ever hearing two words as rhyming. She might even learn to distinguish beautiful landscapes from dreary or ugly ones (even if only in a way that was parasitic on other people's classifications), without a landscape ever looking beautiful to her. There is a sense in which such a person grasps the concepts minor, or rhyming, or beautiful. But there is also a sense in which she does not, or does not fully, grasp those concepts. The same is true for a range of concepts that apply to social interactions. Someone may have a theoretical understanding of what it is for a remark to be insulting or patronising, and he may be able to classify a wide range of remarks as insulting or patronising (or not), without ever experiencing a remark as insulting or patronising. There is a sense in which he grasps the concepts insulting or patronising. But there is a sense in which he does not; just as the person who is not acquainted with fear does not 'shudder out of sympathy' when she sees someone else in a terrible situation, so the person who has never experienced a remark as insulting does not feel a sense of sympathetic indignation or resentment when she sees someone else being insulted.

However, this kind of link between grasping a concept and experiencing things as falling under it does not extend to every case. Consider the concept cancerous. Oncologists and pathologists can see a cell as cancerous; most lay people cannot. But should we say that there is a sense of 'understand' in which understanding the concept cancerous requires the ability to see things as cancerous? It is not clear that we should, because it is not clear why it matters that someone cannot see cells as cancerous, but must rather identify cancerous cells in some less immediate way; it is not clear what that person is 'eo ipso unable to do'. But, for present purposes, we need not determine the limits of the link between grasping a concept and experiencing things as falling under it. It is sufficient to have shown that, for some concepts at least, there is a sense of 'understanding' in which understanding the concept requires the ability to experience things in terms of that concept. That provides one answer to Wittgenstein's question, why the way someone experiences things should matter for her understanding of words and concepts; in some cases, at least, seeing-as really is essential to understanding.

We began the current section with a question: is it true that someone who comes to grasp a new theory or system of concepts thereby comes to see things in a new way? If understanding a concept is a matter of using it appropriately, why should there be any essential connection between one's grasp of concepts and the way one experiences the world? We have explored two responses to that question, developed from strands in Wittgenstein. The first response was that, for every thinker, there must be some concepts that figure directly in the content of her experience; it could not be true that applying concepts always required interpretation. The second response distinguished different notions of understanding and argued that there is a sense of 'understand' in which more is required for understanding a concept than simply applying it appropriately; one must also enjoy appropriate experiences.

Earlier in the paper, I quoted Wittgenstein saying that, when he gives his examples of seeing-as and aspect-perception, he is 'not aiming at some kind of completeness'; nor is he aiming at 'a classification of psychological concepts'; his examples 'are only meant to enable 
W. Child - "Wittgenstein, Seeing-as, and Novelty" - forthcoming in M. Beaney and B. Harrington eds., Aspect Perception after Wittgenstein: Seeing-As and Novelty, London: Routledge.

the reader to cope with conceptual unclarities’ (PPF §202). The point of his discussion is not to advance a comprehensive or explanatory theory of seeing-as; it is to explore the phenomena in a way that will show by example how to achieve the kind of 'overview' or ‘surveyable representation' (PPF §122) that brings philosophical understanding. In that spirit, the current paper is a contribution to understanding the connections between seeing-as and novelty. ${ }^{17}$ 
W. Child - "Wittgenstein, Seeing-as, and Novelty" - forthcoming in M. Beaney and B. Harrington eds., Aspect Perception after Wittgenstein: Seeing-As and Novelty, London: Routledge.

\section{BIBLIOGRAPHY}

Works by Wittgenstein

LW I Last Writings on the Philosophy of Psychology Volume I, eds. G. H. von Wright \& H. Nyman, trans. C. Luckhardt \& M. Aue, Oxford: Blackwell, 1982.

PI Philosophical Investigations, 4th edition, eds. P. M. S. Hacker and J. Schulte, trans. G. E. M. Anscombe, P. M. S. Hacker, and J. Schulte, Oxford: Blackwell, 2009.

PPF 'Philosophy of Psychology: A Fragment', in Philosophical Investigations, 4th edition. (In previous editions, this material appears as Philosophical Investigations Part II. References in the text are given by the $\S$ numbers used in the 4th edition. For a table of correspondences between these $\S$ numbers and the page numbers of earlier editions, see Day and Krebs 2010.)

RPP I Remarks on the Philosophy of Psychology Volume I, eds. G. E. M. Anscombe \& G. H. von Wright, trans. G. E. M. Anscombe, Oxford: Blackwell, 1980.

RPP II Remarks on the Philosophy of Psychology Volume II, eds. G. H. von Wright \& H. Nyman, trans. C. Luckhardt \& M. Aue, Oxford: Blackwell, 1980.

Z Zettel, 2nd edition, eds. G. E. M. Anscombe \& G. H. von Wright, trans. G. E. M. Anscombe, Oxford: Blackwell, 1981.

\section{Other Works}

Boden, M. 2004 The Creative Mind: Myths and Mechanisms 2nd edition, Abingdon: Routledge.

Brewer, B. 2011 Perception and Its Objects, Oxford: Oxford University Press.

Campbell, J. 2002 Reference and Consciousness, Oxford: Oxford University Press.

Child, W. 2011 Wittgenstein, London: Routledge.

Day, W. and Krebs, V. 2010 Seeing Wittgenstein Anew, Cambridge: Cambridge University Press.

Doherty, M. J., \& Wimmer, M. C. 2005 ‘Children’s understanding of ambiguous figures: Which cognitive developments are necessary to experience reversal?’, Cognitive Development, 20, 407-421.

Glock, H.-J. 1996 A Wittgenstein Dictionary, Oxford: Blackwell.

Johnston, P. 1993 Wittgenstein: Rethinking the Inner, London, Routledge.

Kuhn, T. 1962 The Structure of Scientific Revolutions, Chicago: University of Chicago Press.

Mulhall, S. 2001 'Seeing Aspects’, in H-J. Glock ed., Wittgenstein: A Critical Reader, Oxford: Blackwell.

Rock, I., Gopnik, A., \& Hall, S. 1994 'Do young children reverse ambiguous figures?', Perception, 23, 635-644.

Travis, C. 2004 'The Silence of the Senses', Mind, 113, 57-94.

Williamson, T. 2007 The Philosophy of Philosophy, Oxford: Oxford University Press.

Wimmer, M. C., \& Doherty, M. J. 2011 The development of ambiguous figure perception. Monographs of the Society for Research in Child Development, 76(1), 1-130. 
W. Child - "Wittgenstein, Seeing-as, and Novelty" - forthcoming in M. Beaney and B. Harrington eds., Aspect Perception after Wittgenstein: Seeing-As and Novelty, London: Routledge.

\section{NOTES}

1 See Kuhn 1962, chapter 10.

2 Margaret Boden makes similar comments (though without the specific focus on seeing-as), distinguishing between historical creativity and psychological creativity and observing that psychological creativity is the philosophically more interesting phenomenon (see Boden 2004, 2).

3 There are important views of perception on which the character of a subject's perceptual experience is completely independent of the concepts, if any, that she possesses. On some views, the representational content of experience is entirely non-conceptual. On other views, experience itself has no representational content at all (see e.g. Campbell 2002 ch. 6; Travis 2004; Brewer 2011, ch. 5). These views certainly require discussion. For present purposes, however, I simply assume that seeing-as involves experiences with conceptual content - in order to focus on the special issues concerning novelty.

${ }^{4}$ For noticing an aspect, see PPF $§ 113$; for experiencing a change of aspects see e.g. PPF $\S \S 129,130,135,152,257$; for the dawning or lighting up of an aspect, see e.g. PPF $\S \S 118$, 140, 207, 237, 247.

5 See, for instance, Mulhall 2001, 255: 'On my account, [experiences of aspect dawning] constitute only one striking manifestation of continuous aspect perception; and it is this concept - and the general attitude it characterizes - which is Wittgenstein's real concern.'

6 See e.g. Glock 1996, 36 ff.; Johnston 1993, 243-4.

${ }^{7}$ For this case, see PPF §242.

8 See for example PPF §§143-44 and 245. For more on this point, see Child 2011, 185-7.

${ }^{9}$ I owe this point to Naomi Eilan, who discussed it in her presentation, 'Aspect-Seeing and Thinking', at the 'Seeing-As and Novelty' conference at York in 2012. Eilan drew attention in particular to the developmental findings reported in Rock, Gopnik, and Hall 1994, Doherty and Wimmer 2005, and Wimmer and Doherty 2011.

10 Stephen Mulhall takes the contrary view: 'Someone who cannot, for example, see a schematic drawing of a cube first one way then another is someone who cannot continuously see the schematic drawing as a cube either way - she could not stand to such a picture of a three-dimensional object as she does to that object itself' (Mulhall 2001, 254).

11 The German has ‘erkennen' which, like the English 'recognize', can be used in both a perceptual and a non-perceptual, merely cognitive way.

12 For the 'sufficiently fluent participant' formulation, see Williamson 2007, ch. 4.

13 See also Wittgenstein's remark about a person who says that to him the words 'if' and 'but' feel the same: 'If he used the words "if" and "but" as we do, wouldn't we think he understood them as we do?' (PPF §40).

14 The same caveat that was mentioned in note 3 above is needed here; a full defence of this argument would need to consider views of perception on which perceptual experience does not have conceptual content at all.

15 An alternative way of developing essentially the same idea would set things up differently. On this alternative view, understanding a concept never requires more than using it appropriately; but using the concept appropriately may require that one experiences things in a particular way.

16 Compare LW I 198: 'He is incomprehensible to me means that I cannot relate to him as to others.' Wittgenstein gives an example: 'he gets angry, when we see no reason for it; what excites us leaves him unmoved. - Is the essential difference that we can't foresee his reactions? - Couldn't it be that after some experience we might know them, but still not be able to follow them?' (LW I 192) For related comments, see RPP II 568. 
W. Child - "Wittgenstein, Seeing-as, and Novelty" - forthcoming in M. Beaney and B. Harrington eds., Aspect Perception after Wittgenstein: Seeing-As and Novelty, London: Routledge.

17 An earlier version of this paper was presented at the conference on Seeing-as and Novelty at York in 2012. I am grateful to the participants in that conference, and especially to Michael Beaney, for their very helpful comments. 